\title{
Los libros de lectura de la escuela primaria como apoyos didácticos en la formación de valores de los niños mexicanos
}

\section{Elementary School Reading Books as Didactic Support in the Value Formation of Mexican Children}

\section{Elvia Montes de Oca Navas*}

* Sociedad Mexicana de Historia de la Educación (México). Profesora Normalista, Licenciada en Filosofia, Maestra y Doctora en Estudios Latinoamericanos. Entre sus publicaciones más recientes están "Voces magisteriales durante la reforma educativa de 1934: el caso del Estado de México", (2020). Obtuvo la medalla Gabino Barreda por el más alto promedio de calificaciones al término de sus estudios como Doctora en Estudios Latinoamericanos en la Facultad de Ciencias Politicas y Sociales de la UNAM (1990). Sus líneas de investigación son historia de la educación en México, especialmente durante el gobierno de Lázaro Cárdenas; libros escolares y estudios de género. Correo electrónico: elvia.montesdeoca@gmail.com

(1) https://orcid.org/0000-0001-8526-3210

Historial editorial

Recibido: 06-septiembre-2019

Aceptado: 18-diciembre-2019

Publicado: 31-enero-2020

ISSN-e: 2594-2956 
Los libros de lectura de la escuela primaria como apoyos didácticos en la formación de valores de los niños mexicanos

\section{Resumen}

En esta investigación se hace un análisis comparativo entre los contenidos de diversos libros de lectura para sexto grado de primaria. Unos fueron utilizados durante el cardenismo, otro dos décadas después y el texto escolar actual. Se plantean y responden algunas preguntas sobre los objetivos que pretendían lograr en los alumnos lectores, especialmente con respecto a su formación moral y cívica. Dos textos fueron elaborados por autores individuales, uno por la Comisión Editora de la Secretaría de Educación Pública (SEP) y otro más por Ma. Enriqueta Camarillo. El objetivo de la investigación fue encontrar las semejanzas y diferencias en las finalidades educativas, más allá de la práctica de la lectura. Se logró, a través del análisis y comparación de los contenidos de las obras, llegar a conclusiones que demuestran el peso que tuvieron en la configuración cívica y moral de los educandos.

Palabras Clave: libros escolares, libros de lectura, sexto grado de primaria, reforma educativa, formación cívica y moral. 


\title{
Elementary School Reading Books as Didactic Support in the Value Formation of Mexican Children
}

\begin{abstract}
In this research we present a comparative analysis of the content of several elementary school reading books for sixth grade. Some books were used during Cardinalism, another two decades later and the current school text. We questioned what the objectives were that these books intended to achieve in student readers, especially with regard to their moral and civic training. Two of these texts were presented by individual editors, one by the Publishing Commission of the Ministry of Public Education (SEP) and another by Ma. Enriqueta Camarillo. The objective of the present research was to compare and contrast the educational purposes of these text books, beyond the practice of reading. It was possible, through the analysis and comparison of the contents of the works, to reach conclusions that demonstrate the weight that these books had on the civic and moral configuration of the students.
\end{abstract}

Keywords: school books, reading books, sixth grade elementary school, education reform, civic and moral formation 
L'école primaire lisant des livres comme supports didactiques dans la formation des valeurs des enfants mexicains

\section{Résumé:}

Dans cette recherche, une analyse comparative est faite entre le contenu de divers livres de lecture pour la sixième année du primaire, certains ont été utilisés pendant le cardinalisme, deux décennies plus tard et le texte actuel de l'école. Tout au long de celle-ci, certaines questions sont posées et répondues au sujet des objectifs que ces livres entendaient atteindre chez les étudiants lecteurs, notamment en ce qui concerne leur formation morale et civique. Deux livres de ceux analysés ont été préparés par des auteurs individuels, un par la Commission de rédaction du ministère de l'Éducation publique (SEP), un autre par Ma. Enriqueta Camarillo, finalement analysés et comparés avec le texte du SEP d'aujourd'hui. Les objectifs du travail étaient, à travers ces textes scolaires, de trouver des similitudes et des différences par rapport au rôle qu'ils avaient l'intention de jouer dans la formation des élèves, pas seulement dans la pratique de la lecture. Il a été possible, à travers l'analyse et la comparaison du contenu des travaux, de tirer des conclusions valables qui démontrent le poids que ces livres ont mis sur la configuration civique et morale des étudiants.

Mots-clés: Manuels scolaires, Livres de lecture, Sixième année, Réforme de l'éducation, Formation civique et morale. 
Czytanie książek w szkole podstawowej jako nauczanie wspierajace w tworzeniu wartości meksykańskich dzieci

\section{Streszczenie:}

Tekst dokonuje analizy porównawczej między treścią różnych książek do czytania dla szóstej klasy szkoły podstawowej, niektóre były używane podczas cardenizmu, kolejne - dwie dekady później i tekst obecny. W artykule sa zadawane pytania i szukane odpowiedzi na temat, które książki zdolaly wplynac na formacje moralnej i obywatelskiej uczniow. Dwie z analizowanych książek zostały przygotowane przez poszczególnych autorów, jedna przez Komitet Wydawniczy Sekretariatu Edukacji Publicznej (SEP), druga przez Ma. Enriqueta Camarillo i są analizowane, i porównywane $\mathrm{z}$ tekstem dzisiejszego SEP. Celem pracy było, poprzez teksty szkolne, znalezienie podobieństw i różnic w odniesieniu do roli, jaką zamierzalo odgrywać panstwo w kształciniu uczniów, nie tylko w praktyce czytania. Poprzez analizę i porównanie treści prac można było wyciągnąć ważne wnioski, które pokazują wagę, jaką książki mialy na formowanie sie obywatelskiej i moralnej konfiguracji uczniów.

Słowa kluczowe: Książki szkolne, czytelnictwo, szósta klasa, reforma edukacji, formacja obywatelskia i moralna. 


\section{Introducción}

Pensar y ser un inconforme son sólo dos maneras de nombrar lo mismo (De la Borbolla, 2019, p. 29).

Con relación al estudio de los valores y el peso de la crítica, Óscar de la Borbolla escribe:

La crítica es esa modalidad de pensar por la que los valores llegan al mundo y, gracias a ello, este se hace discernible: se presenta como un orden donde los seres se jerarquizan de lo mejor a lo peor, de lo bueno a lo malo, de lo bello a lo horrendo, de lo odiado a lo amado (De la Borbolla, 20I9, p. 28).

Porque existe lo distinto y gracias a la crítica, tenemos la oportunidad de elegir, la elección confirma la existencia de la libertad humana, aunque su ejercicio supone otras muchas condiciones.

Criticar, poner en crisis, descubrir los rincones por donde el pensamiento puede viajar para romper lo homogéneo, lo aparentemente parejo y sin fisuras; poner en duda lo que aparece enfrente como único y total, definitivo y acabado, esta es la inconformidad del pensar. Las verdades y el avance del conocimiento no surgen de la certeza, sino de la duda que nace de la insatisfacción del saber, se sabe que no se sabe lo suficiente; no surge de la ignorancia absoluta de quien ni siquiera sabe que no sabe. "La pregunta es el comienzo de la solución del problema" (De la Borbolla, 20I9, p. 59).

148 Las reflexiones filosóficas de Óscar de la Borbolla, basadas en los clásicos como Sócrates o en los modernos como Descartes, invitan a volver a lo antes estudiado, utilizando otras perspectivas teóricas, así como nuevas fuentes de investigación, para retornar a preguntar, incluso cuestionarse a sí mismo, y hallar nuevas respuestas a lo antes estudiado. En el documento se analiza un tema sobre el que ya se han 
escrito y publicado diversos trabajos: los libros escolares, pero el asunto se reduce y profundiza en cada investigación. Aquí se aborda el estudio de los materiales de lectura de sexto grado de primaria, utilizados en el periodo presidencial de Lázaro Cárdenas, 1934-1940, cuya etapa es importante en la historia de la educación en México porque se aplica la educación socialista.

Se realiza un comparativo de los libros de la etapa socialista con el de Rosas de la infancia. Sexto año de Ma. Enriqueta Camarillo y con el que actualmente utilizan los alumnos de sexto grado de las escuelas primarias del país, y que fue editado por la SEP. Se revisan aspectos relacionados con los valores cívicos y morales de la época, así como su enfoque ideológico. El análisis y la comparación se utilizan como métodos de estudio y las fuentes de información corresponde con los mismos textos.

El Plan Sexenal 1934-I940, en la reforma al Artículo $3^{\circ}$ de la Constitución General y el mismo presidente Cárdenas exponían lo que la educación significaba en aquel momento. En un discurso el primer mandatario dijo:

Conceptúo que la implantación de la escuela socialista que señala el plan sexenal, intensificará la obra cultural que la Revolución ha emprendido para la emancipación del pueblo laborante, preparándolo científica y socialmente (Cárdenas, I978, p. I33).

Para comprender las finalidades educativas en cada etapa de la historia, es necesario precisar que el sexto grado de primaria corresponde al término del nivel y donde los alumnos -con alrededor de I2 años de edad- terminan el segundo bloque de la educación básica y pasan al último: la educación secundaria. ¿Qué leían, o se supone que leían, los niños y los maestros, tal vez los padres de familia en la reforma educativa de 1934 y años siguientes?, ¿qué leen hoy, o se supone que leen?, ¿cuál es el proyecto educativo y de nación que se manifiesta en estos libros?, ¿cuáles son los valores cívicos y morales que se inculcan?, 
$¿$ existe una carga de valores identificados como superiores y por ellos imitables en estas lecturas?, ¿cuáles son los valores históricos y el concepto de historia misma que contienen estos recursos escolares? Estas son las principales preguntas que guían la investigación y que serán respondidas a lo largo de ella.

\section{Estado de la cuestión}

El tema de los libros de texto en México ha sido un asunto bien estudiado. Investigadoras como Elsie Rockwell, Mary Kay Vaughan, Luz Elena Galván Lafarga y María Guadalupe Mendoza Ramírez, han realizado importantes trabajos sobre esta materia, resaltando en ellos la importancia que estos recursos didácticos han tenido en la historia de la educación en México, no sólo como materiales escolares, sino también para el enriquecimiento cultural de los niños y, de manera explícita o no, para la orientación ideológica y axiológica.

A nivel internacional existe el Centro de Investigación sobre Manuales Escolares (MANES), que ha promovido y realizado múltiples investigaciones sobre textos escolares en España y en diversos países de América Latina, incluido México. La sede del organismo es la Universidad Nacional de Educación a Distancia (UNED), de Madrid, España, y está dirigido por la Dra. Gabriela Ossenbach. La consulta de estos trabajos es indispensable para quien investiga sobre el tema.

Ubicándonos en México, Elsie Rockwell es quien ha trabajado de manera profunda la zona de Tlaxcala y Puebla, con respecto al gobierno de Cárdenas. La autora afirma: "La movilización popular cardenista en sí fue una educación política para grandes sectores populares del país, y sus repercusiones continúan vivas hasta la fecha" (Rockwell, I996, p. 4). En sus trabajos analiza qué se hizo con los textos escolares en una región indígena náhuatl del México central -correspondiente al estado de Tlaxcala, región de la Malintzi- y cómo fueron aceptados o rechazados en las escuelas rurales de la zona. 
Luz Elena Galván Lafarga hizo interesantes estudios sobre libros escolares e impulsó a otros investigadores para hacer trabajos semejantes. Analizó los materiales de historia de México e historia patria que fueron utilizados durante I934 y I939; en los cuales se rescatan mitos y arquetipos "tradicionales" con los que se construyen los imaginarios sociales, todo en pos de la formación de una identidad nacional en los niños (Galván, 2004).

Mary Kay Vaughan en sus investigaciones insiste de manera reiterada en el concepto de negociación como herramienta de análisis para entender mejor lo que sucede entre los diversos actores que participan en la educación de los niños, de tal manera que en la realidad se dan “ajustes" que permiten llevar a cabo el fenómeno educativo; considerado como un proceso no lineal en el que, a lo largo de la historia, se han dado revisiones y reinventado las políticas públicas emanadas de un Estado central y controlador (Vaughan, 2000).

María Guadalupe Mendoza (2009) concluye que los libros de historia funcionaron como herramientas educativas y como discursos unificadores de la historia, a partir de un proyecto estatal central.

Laura Giraudo (2004) analiza lo referente a lectores campesinos, maestros indígenas y bibliotecas rurales en las décadas de los 20 y los 30 del siglo pasado en la región de Puebla y Veracruz. La investigadora encuentra que los libros escolares tenían diferentes contenidos, ideologías y proyectos sociales. Cita como ejemplos los textos Simiente de Lucio Tapia, correspondientes a la serie para escuelas rurales editada durante el gobierno de Cárdenas, y el de Rosas de la infancia de Ma. Enriqueta Camarillo.

El asunto de los libros escolares está presente también como tema de investigación en los eventos que realiza periódicamente el Consejo Mexicano de Investigación Educativa (COMIE) y la Sociedad Mexicana de Historia de la Educación (SOMEHIDE). Por citar un ejemplo, en el XV Encuentro Internacional de Historia de la Educación, realizado en 2018 en la ciudad de Pachuca, se presentaron varios trabajos 
relacionados con libros de lectura y con la educación socialista. Una propuesta interesante y novedosa fue la de Marco de Luca, quien hizo un análisis comparativo entre los materiales de lectura utilizados en Italia y México durante la década de los treinta del siglo pasado, especialmente bajo los gobiernos de Benito Mussolini y Lázaro Cárdenas, respectivamente (Luca, 20I8).

De manera general los investigadores llegan a conclusiones semejantes en relación a que los textos escolares -especialmente los de lectura e historia- contienen concepciones ideológicas y conceptos morales, religiosos, políticos, históricos, sociales, antropológicos, etc., que no siempre aparecen de forma abierta y explícita; pero sí de manera eficaz para influir en el pensamiento y la conducta de los infantes. Los libros escolares, en los que se hace concreta la cultura de cada pueblo y cada época, son un elemento fundamental para la formación de una conciencia nacional en los alumnos y su identificación con un pueblo, una Patria, una historia y una cultura.

\section{Libros escolares de lectura de la escuela socialista}

Partamos de la función que Alain Choppin reconoce en los textos escolares: "[...] tienen una función ideológica y cultural: aculturar y adoctrinar a los lectores, lo cual puede ejercerse de manera explícita, esquemática o desmedida, o aun de manera indirecta, subrepticia, implícita pero nunca menos eficaz" (Alain Choppin, citado en Montes de Oca, 20Io, p. 338).

Los libros de la escuela socialista rechazaban los textos enciclopédicos destinados a ser leídos, más que comprendidos. Buscaban acercar a los niños a la realidad social en la que se desenvolvían, sin desconocer otras realidades en que vivían otros infantes de su misma edad; aprender para la vida, no para el lucimiento de los eruditos; y promover la formación de una sociedad y escuela laicas, lejos de cualquier influencia religiosa. 
Durante el cardenismo se recomendó no leer la serie Rosas de la infancia de Ma. Enriqueta Camarillo, que fue elaborada cuando la autora vivió en el extranjero. Los libros eran de pasta gruesa y con ilustraciones del famoso pintor Germán Gedovius (I867-I937). Aunque los destinatarios son niños mexicanos, los protagonistas de las lecturas son niños rubios como el sol y de ojos azules como el mar, quienes viven en cómodas y grandes casas de hermosas ciudades (ver figura I).

El campo, un campo idílico, se describe como una fuente de tranquilidad y trabajo; familias modelo, disciplinadas, viviendo en un país que iba con pasos seguros hacia la modernización industrial; cada uno ocupando su puesto, en la familia y en la sociedad, donde Dios estaba presente como hacedor de todo lo que es y como director de los destinos de cada ser humano. Se habla de las diferencias sociales que existen en el México de entonces, pero no hay condena ni crítica, sólo están ahí, y ahí han estado siempre.

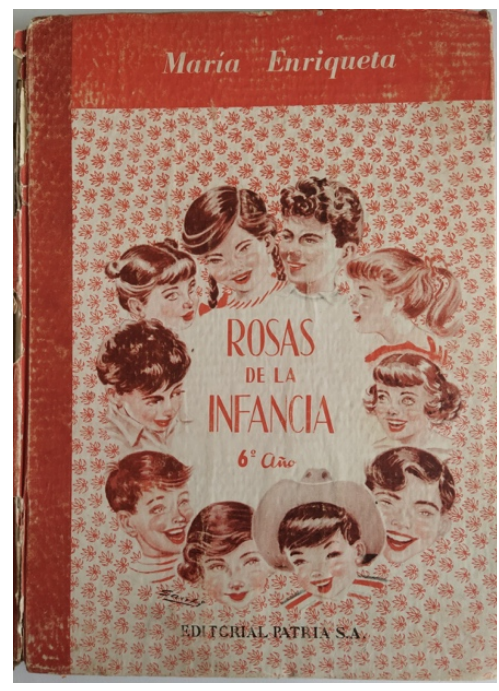

Figura I. Portada del libro Rosas de la infancia, de María Enriqueta.

En los libros de lectura del cardenismo desaparece el idealismo. Los personajes infantiles, tanto en el campo como en la ciudad, viven día a 
día lo difícil de su existencia, niños pobres que viven en casas pobres, barrios pobres, hijos de obreros y campesinos pobres, que ven en las calles de la ciudad y del campo las injusticias y desigualdades en el reparto de las riquezas materiales entre los que trabajaban y los dueños del capital, que conocen lo que el gobierno en turno -el encabezado por Cárdenas- estaba haciendo para paliar esta situación y procurar mejores niveles de vida para los trabajadores: la reforma agraria y el reparto de ejidos, la defensa y aplicación justa de los derechos de los obreros, la expropiación de la industria petrolera, la educación socialista y su proyecto para una sociedad más justa e igualitaria... Estos son los temas principales, especialmente en los libros de lecturas de sexto grado, y es obvio que se oponían al contenido que manejaban en Rosas de la infancia.

Los libros coinciden en dar a la familia la importancia que tiene como la base principal sobre la que se sostiene la sociedad; sin embargo, y de acuerdo con los principios de la escuela socialista, en sus contenidos nada es natural y eterno, todo es histórico y tiene causas materiales que lo provocan. Las ciencias, alejadas de todo elemento no científico, serían las encargadas de explicar todos los fenómenos sociales y naturales de manera "racional y exacta", como lo estableció la reforma constitucional al Artículo $3^{\circ}$ de 1934 . A partir del conocimiento científico del pasado y del presente, los niños podrían construir un futuro mejor, especialmente aquellos cuyas condiciones de vida eran más difíciles. Conociendo las causas de los fenómenos naturales y sociales, existía la posibilidad del cambio para obtener resultados diferentes y mejores para todos.

La escuela primaria reconoce como eje de todas sus labores las actividades del trabajo productivo y socialmente útil: la escuela socialista haría que los educandos adquirieran una cultura básica, utilitaria, dirigida al servicio de la colectividad; ejercitaría también a los educandos en el gobierno de la escuela basado en la autodisciplina; procuraría que mediante hábitos apropiados se identificaran con la clase obrera [trabajadores, campesinos y obreros]; aprovecharía al mismo tiempo la coeducación para 
dignificar y liberar a la mujer; finalmente, desarrollaría fecunda y generosa labor para mejorar a los trabajadores (Meneses, I988, p. 147).

En los documentos oficiales y no oficiales, este era el proyecto de la escuela socialista a partir de la educación primaria, que era ya obligatoria. Estos principios conductores de la reforma cardenista debían reflejarse en los libros de texto, en este caso los de lectura, donde los alumnos podrían revisar sus contenidos cuantas veces quisieran, guiados por sus profesores.

La Secretaría de Educación Pública en el periodo cardenista tuvo como primer titular a Ignacio García Téllez (1934-I935). Fue él quien solicitó al Consejo de Educación Primaria, órgano consultivo de asuntos relacionados con el nivel, convocara a la elaboración de propuestas para los nuevos libros escolares, los cuales serían medios idóneos para acercar a los niños a las ciencias, alejándolos de las ideas supersticiosas y fantasiosas manejadas en los textos anteriores. Debían enfocarse en propuestas que hablaran sobre la naturaleza y la sociedad de manera racional y exacta, que ubicaran a los alumnos en el momento histórico que les tocaba vivir y que generaran la necesidad de cambiar su realidad a partir de la participación activa y comprometida de todos, incluidos por supuesto los estudiantes. Los contenidos de los nuevos materiales debían ser temas abiertos y directos sobre la organización de la sociedad con base en clases sociales, sus causas y desarrollo histórico, sus consecuencias y posibilidades de cambio que -por supuesto- no se lograba con los libros existentes hasta entonces (Rosas de la infancia) donde los duendes, las brujas, las hadas y las niñas "bien" luchan entre sí, con el triunfo invariable "del bien sobre el mal". Así no era el mundo en el que se movía la mayoría de los niños mexicanos de entonces, tampoco sus padres y el medio en el que crecían.

Con la reforma de 1934 se diferencian los libros dedicados a los niños para escuelas urbanas y rurales que, si bien los propósitos eran los mismos, la realidad en la que se desenvolvían era diferente. Para I936I937 aparecieron los textos de la Serie SEP, dirigidos a escuelas urbanas, 
que fueron elaborados por la Comisión Editora Popular y revisados y autorizados por el presidente Cárdenas. En las primeras páginas aparecía un oficio con la firma del mandatario federal en el que se leía que, después de su revisión, se daba la autorización respectiva a esta obra porque "[...] los principios pedagógicos que en ella se aplican, así como los asuntos que comprende y la forma literaria empleada en su desarrollo responden a las normas fijadas a la Escuela Mexicana y a la finalidad asignada a la misma" (SEP, 1936, s/p).

En los libros de la Serie SEP no aparecen los nombres de los miembros de la Comisión Editora Popular, pero esta estaba integrada por Antonio Luna Arroyo, presidente; Manuel Mejía, secretario; Federico Briones, Luis Chávez Orozco, Rafael Ramírez, Atenógenes Pérez y Soto y Juan de Dios Bátiz (Meneses, 1988). Se supone que todos estaban convencidos de la reforma educativa y eran activos participantes en ella. Sin embargo, los textos de esta serie no fueron los únicos que se leyeron entonces. Luis Hidalgo Monroy, profesor de la Escuela Normal de Veracruz, fue autor de la serie ¡Levántate! y -según el autor- en ellos se expone la moderna ideología social, para que el alumno tenga “[...] una visión clara de los problemas sociales que agitan a su país y con los cuales irá a ponerse en contacto desde luego" (Hidalgo, I938, p. 7). El compilador y autor reconoce abiertamente la carga ideológica de los contenidos de esta obra:

[...] este libro da a conocer al niño: cómo se ha formado el proletariado, cómo, cuándo y dónde nació el poder burgués, qué ha dado origen a la lucha de clases, cuáles son las ventajas alcanzadas por los trabajadores y cómo las han conseguido, cómo se forman los sindicatos y el contenido de la Legislación obrera (Hidalgo, 1938, p. 7).

Este fragmento es parte del prólogo escrito por el autor. En él menciona que el materialismo histórico es el método utilizado en la explicación de la historia social y está dedicado a los niños de escuelas públicas, hijos de trabajadores, no a los de las escuelas particulares, hijos de burgueses. Esta polarización hizo pensar a quienes vivieron esta época 
que, si se ahondaban estos mensajes sobre las diferencias y las clases sociales, se podía llevar al país a una guerra civil de proletarios contra burgueses, pero afortunadamente esto no fue así.

Las lecturas debían hacerse en silencio y los alumnos respondían los cuestionarios que aparecían al final de ellas. El profesor debía provocar la discusión entre los estudiantes, absteniéndose de dar respuestas definitivas a sus preguntas. Debían excluir toda intervención religiosa y apoyarse únicamente en las ciencias y la razón. Los hechos y las historias contenidas en las lecturas ayudarían a los alumnos a elaborar sus propios juicios, para juzgar las acciones humanas con base en una tabla de valores que les indujera a imitar lo positivo y rechazar lo negativo. Debían conducir al alumno a ser un hombre útil para sí mismo, su familia y su Patria, que conociera los derechos y obligaciones que imponía vivir en sociedad. Se explica que la revolución que entonces se estaba realizando como "método de lucha", era para cambiar la estructura económica, política y social de un país (Hidalgo, 1938). En una ilustración del mismo texto muestra al presidente Cárdenas frente a un sembrado, acompañado de campesinos y rodeados por arados, caballos, surcos y árboles. La Revolución mexicana es definida como socialista por excelencia, que en el campo estaba destruyendo el latifundio y en las fábricas mejoraba las condiciones de trabajo del obrero; el predominio de lo colectivo sobre lo individual, todo con apego a las leyes establecidas, especialmente lo estipulado en la Constitución general de I9I7 y en el Plan Sexenal I934I940.

Se habla del capital como producto del trabajo humano, su acumulación en unas manos y su mala distribución, la explotación del hombre por el hombre, la usura y el mal manejo de los capitales, la burguesía dueña de la riqueza y del poder, la lucha de clases, diversas formas de sociedades en la historia con base en la organización del trabajo y la producción de la riqueza. Se incluyen fragmentos del Código Agrario de 1934 y de la Ley Federal del Trabajo de I93I, del reglamento laboral para la organización de sindicatos y contratos 
colectivos. Conocimientos útiles no sólo para el alumno de sexto grado, sino también para sus padres trabajadores.

En otro libro de entonces, México, de Francisco Cuervo Martínez (ver figura 2), el autor aporta datos personales que lo identifican como un personaje importante del momento, pues fue director de la Escuela Nacional para Maestros del Distrito Federal, inspector General de Educación Primaria en la República, catedrático de la Escuela Nacional Preparatoria y del Colegio Militar e inspector de Educación Primaria de la Ciudad de México.

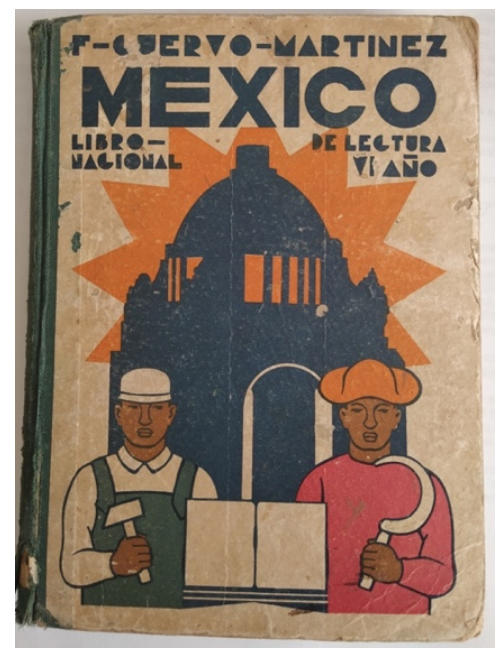

Figura 2. Portada del texto México, libro de lectura de Francisco Cuervo Martínez.

El libro inicia con un fragmento de la obra de Alfonso Reyes: "El paisaje del Anáhuac, donde el aire brilla como espejo". Con estas lecturas, los 158 alumnos debían adquirir el arte del bien hablar, de ahí el lenguaje cuidadoso que se utiliza en ellas. Los conceptos de Patria y valores patrióticos están en toda la obra, el papel de quienes quieren reformar y cambiar el sistema social existente. 
El autor-compilador reúne trabajos de autores mexicanos, latinoamericanos y de él mismo, aunque en diversas lecturas sólo escribe sus iniciales (F. C. M.), especialmente en las que tocan asuntos sociales de la época. La selección de textos lleva un marcado tinte ideológico, por ejemplo, del libro de J. E. Hernández Dávalos, Colección de apuntes para la Historia de México, transcribió la Proclama de Morelos, donde el insurgente ordena el reparto de tierras a los pobres de los pueblos campesinos: "El repartimiento que tocare a los vecinos de dichas poblaciones ha de hacerse con la mayor economía y proporción, de manera que nadie enriquezca en lo particular y todos queden socorridos en lo general" (Cuervo, I936, p. 55).

En las lecturas se incluye el Artículo 27 constitucional referente a la propiedad y reparto de tierras y aguas dentro de los límites de la nación mexicana. En nota del compilador se dice que:

El maestro explicará amplia y pormenorizadamente este Artículo, haciendo comentarios sobre cada uno de sus incisos, e ilustrándolos con hechos y sucesos relacionados con los mismos. Los alumnos lo leerán repetidas veces hasta comprender perfectamente su ideología y asimile sus contenidos (Cuervo, I936).

Lo mismo ocurre con respecto al Artículo 123 constitucional, relacionado con la legislación laboral y cabría cuestionar si los alumnos, inclusive los maestros, ¿estaban preparados para entender los contenidos, alcance y logros de estas reformas legislativas? Se hace hincapié en la injusta distribución de la riqueza, como en el caso de la tierra, lo que significaba la reforma agraria y el importante reparto de ejidos que el presidente Cárdenas realizaba entonces.

Lecturas referentes a los avances de la tecnología moderna, las comunicaciones terrestres, la radio, la electricidad, los inventos del momento, el trabajo como única fuente de riqueza. La lección Qué es el socialismo, firmada por F. C. M., habla de proletarios y propietarios, sus 
diferencias, así como de los sistemas capitalista y socialista. A este último lo califica de humanitario:

[...] una repartición justa de los medios e instrumentos de producción, y una distribución equitativa de los productos obtenidos mediante el trabajo, para corregir los malos efectos del sistema capitalista actual, a todo esto es a lo que se llama SOCIALISMO (Cuervo, I936, p. 45).

¿Qué tanto un niño de sexto grado de entonces, aun con la ayuda de su profesor y de sus compañeros, podía entender suficientemente esto?

En la lección Individualismo, socialismo, comunismo, autografiada con las mismas iniciales (F.C.M.), se lee: "El comunismo es el socialismo radical, el que quiere la absoluta o completa destrucción o desaparición de la propiedad privada de todos los bienes" (Cuervo, I936, p. I05). Entonces, con base en estas lecturas, ¿realmente se estaba preparando a los niños para el futuro cambio social por los rumbos del socialismo y el comunismo, como lo afirmaban los detractores y enemigos de la reforma educativa? Estos materiales preocuparon a personas de la época, de la misma manera que los contenidos que tocaban temas sexuales, en los que se explicaba a los alumnos el desarrollo humano, sus características y cuidados. La pubertad se presentaba como una etapa distinta, pero controlable.

Otras lecturas narran la historia del comercio y la industria en México, que estaba en manos casi siempre de extranjeros, así como sobre la necesidad de crear una nueva sociedad basada en la justicia, la libertad y la igualdad. También, tocan la neutralidad del Estado laico mexicano, ajeno a cualquier dogma religioso, que vela sólo de la aplicación correcta de la Constitución. En algunas lecturas se alude a los discursos de Cárdenas, en los que se reitera el carácter de la nueva educación cercana a las ciencias y alejada de todo prejuicio religioso. ¿Qué tanto los niños entendían estos contenidos?, ¿qué tanto los maestros "socialistas" comprendían estos contenidos y estaban convencidos de su veracidad y conveniente difusión entre los alumnos? 
Otro ejemplo de estos novedosos contenidos es la lectura titulada Por la humanidad del futuro de José Ingenieros:

Los niños son la sociedad del porvenir; fuera delito sembrar en sus cerebros simientes erróneas del pasado. No les enseñéis prejuicios que vosotros mismos habéis dejado de creer. El fanatismo y la intolerancia son los viejos odres de la era que agoniza; no coloquéis en ellos el vino nuevo (Cuervo, I936. p. I79).

El autor habla así a los maestros de la nueva escuela socialista, con miras a un México más justo e igualitario.

En el libro Sexto Año. Serie SEP, que inicia con una lectura denominada De interés general, se alude a los nuevos rumbos de la escuela socialista, dirigida a la adquisición de un concepto racional y exacto del universo y de la vida social, hacia donde se dirigían los contenidos de los textos utilizados por los alumnos en ese periodo. Se puede discutir la subjetividad, ambigüedad, imprecisión y hasta la imposibilidad de alcanzar ese objetivo, pero está explícito, cosa que no ocurre en los actuales libros de lectura para sexto grado.

En los materiales utilizados para 1940 cobra importancia la organización de las escuelas en agrupaciones y comisiones formadas y asumidas de manera voluntaria, como ocurría en el resto de la sociedad, lo cual rompía con el individualismo existente hasta entonces.

[...] luego la finalidad de romper viejos moldes utilizando una labor colectiva, de conjunto, que practicando la autocrítica desplazara anacrónicos prejuicios y obligara a crear un concepto de responsabilidad social que el individualismo ahoga ignorándolo (SEP, I940, p. 8).

Los contenidos de las lecturas, de acuerdo con la metodología y la didáctica modernas, irían graduados en cuanto a su dificultad y nivel de abstracción. Los relatos debían acercar a los lectores a la realidad social en que vivían, tanto en la escuela como fuera de ella, y conectar a los 
alumnos con los problemas económicos y sociales de entonces, para crearles una conciencia social comprometida, junto con los conceptos de cambio y transformación.

A los profesores se les dan indicaciones de orden pedagógico, con el fin de obtener el máximo provecho de las lecciones, no sólo en el manejo y comprensión con los alumnos, sino para que hicieran suyas las ideas y se reflejaran en su conducta diaria. Al inicio del libro se asienta que: "Imprescindible es comprender con claridad el problema de la liberación del hombre en los términos de la realidad social" (SEP, I940, p. II) y se invitaba a desarrollar un espíritu práctico y luchador en los alumnos. A los maestros se les recomienda fomentar en sus discípulos la lectura oral y en silencio, el debate grupal de ideas, llevar un cuaderno de trabajo con cuestionarios referidos a las lecturas, fomentar el manejo de diccionarios y realizar excursiones a fábricas, museos, talleres, sindicatos, periódicos y bibliotecas. Las lecturas -se dice- no eran norma ni para los maestros, ni para los alumnos y solo se consideraban como guías de preparación para el cambio social esperado.

Desde la primera lectura se impone una realidad social: los padres incluidas las madres- tienen que trabajar para sostener a la familia. Así se lee y observa en la lección referente a las inscripciones de los alumnos y el primer día de clases, donde además de los padres de familia que están haciendo fila para inscribir a sus hijos, se ve a niñas mayores registrando a sus hermanos pequeños, porque sus mamás no pueden hacerlo por estar trabajando. En un diálogo el padre dice a la maestra: “-Ya sabe usted. Es bueno el chico. Me tiene contento. Ojalá que así siga. En casa ya lo estamos necesitando para que ayude" (SEP, I940, p. I6).

Si bien se despiertan esperanzas de un futuro mejor, tanto en los adultos como en los niños, el ascenso social no sería automático. En las lecturas, como en el resto de los libros, los niños del campo y la ciudad quieren crecer pronto para ayudar a sus papás en las tareas productivas. El niño obrero -cuando crezca- quiere ser obrero, lo mismo que el hijo 
del campesino; la movilidad social no se observa claramente, sin embargo, las condiciones de trabajo y las relaciones sociales a las que aspiraban eran diferentes, gracias a la organización de los trabajadores y a un gobierno central que apoyaba sus demandas y que confiaba en la educación como palanca para el desarrollo social.

Los niños que aparecen en los textos son nombrados y se nombran entre sí como "camaradas". Los alumnos de sexto grado, igual que sus padres, debían acabar con las fantasías que sólo siembran falsas ilusiones, como el cuento de los Reyes Magos. En los libros tenía que mostrarse la realidad en que vivía la mayoría de los niños, a través de lecciones que hablan de padres responsables y trabajadores frente a otros viciosos, golpeadores y desobligados; conversaciones entre niños de diferentes hogares compartiendo sus experiencias de vida. El vicio, como en el caso del alcoholismo, además de que tenía que ser rechazado, debía ser explicado como todo fenómeno social, buscando la relación racional causa-consecuencia. Se lee en un pasaje que, quien bebe lo hace "[...] para ahogar su desesperación de pobre explotado y que, como él, millones de obreros apelan a la embriaguez como un atenuante que les hace olvidar su dolor y su miseria" (SEP, I940, p. 23). El alumno debía reflexionar sobre cómo cambiar esta problemática social. Las preguntas, comparaciones, discusiones y opiniones debían fomentarse por el maestro, quien se abstendría de imponer su visión como la única y acabada. Él era considerado uno más de los que participan en clase.

Se incluyeron lecciones referidas a la higiene personal y del ambiente, el cuidado de la salud, la revisión periódica con el médico, la responsabilidad de cuidar cada quien de sí mismo y de los demás en pos de un futuro mejor, como se aprecia en la siguiente cita:

Cuando los niños no tengan obligaciones que perjudiquen su salud, cuando posean todo lo que necesitan para convertirse en hombres sanos y nada les robe la alegría de vivir, entonces la humanidad habrá puesto los sólidos cimientos de un mundo mejor (SEP, I940, p. 29). 
En las escuelas había reuniones periódicas de alumnos, padres y maestros para la discusión de problemas que no solamente correspondían al ámbito escolar. Se planteaban probables soluciones pasadas en la cooperación de todos y a partir de responsabilidades libremente asumidas. Se recomendaba el establecimiento de bibliotecas escolares en las cuales toda la comunidad definiría qué libros la integrarían, instalación de talleres; así como la operación de cooperativas de producción y de consumo, donde los beneficios obtenidos serían repartidos de manera proporcional al trabajo realizado por cada participante.

Otras lecturas se referían a las diversas maneras en que vivían los niños y a las labores productivas, de acuerdo a las zonas geográficas del país; así como a las actividades y condiciones de los trabajadores en las minas y las fábricas. Incluían relatos de autores como León Tolstoi, referentes a la explicación que da un niño de familia rica sobre la pobreza de algunos y la riqueza de otros: "los pobres son pobres porque no trabajan" y la reflexión que hace el niño pobre al no entender esto, pues su padre trabaja mucho más que el papá del niño rico. Entonces, ¿qué pasa?

Los grandes avances de la ciencia y del trabajo humano para el mejoramiento de las sociedades también estaban presentes. La construcción de puentes y grandes obras para beneficio de todos, el uso de las máquinas en la producción y las características de la revolución industrial. Se buscaba mostrar “[...] cuán grande y poderoso es el talento del hombre aplicado al estudio" (SEP, I940, p. 66). Aparca el hombre como producto de la sociedad y se asienta que: "[...] no hay nada en el mundo, por alto que esté, que la voluntad tenaz y firme de un pueblo, 164 no pueda alcanzar algún día" (SEP, I940, p. 74). Esta última idea es la respuesta que ofrece una lectura a quienes asumen actitudes derrotistas frente a los problemas y quienes utilizan como argumento fundamental para justificar su pasividad, que las cosas no pueden cambiar porque Dios así las hizo. 
Frente a la visión colonialista, etnocéntrica y fatalista de la conquista de México, donde se consideraba que se impuso lo superior sobre lo inferior -según la visión que manejó el libro de María Enriqueta Camarillo- el libro de la SEP (I940) ofrece una visión histórica diferente y así se deduce de una carta que maneja una lección, donde un campesino escribe a su hijo:

Recordarás que en otra ocasión me hablabas del triste papel que jugó nuestro indio en la conquista de México, pues con los conquistadores vino una larga cadena de monjes, agentes del aventurero y codicioso español, que usaron su doctrina como droga para adormecer todo impulso libertario; esclavizaron la voluntad del indio y lo sometieron a la explotación del encomendero, a quien no le preocupaba otra cosa que la rapiña de las riquezas del suelo cuyo legítimo dueño no era (SEP, I940, pp. 8o-8I).

El origen de la propiedad privada y la apropiación de la riqueza, como es el caso de la tierra, también es tema de análisis. Aparece el pobre que construye casas grandes y hermosas para otros, cuando él no tiene siquiera una pequeña donde vivir, a diferencia de las aves que construyen su propio nido. Trata la existencia de monopolios y su calidad de injustos, la acumulación de la riqueza en pocas manos, el desarrollo del capitalismo y sus contradicciones y crisis históricas, la sobreproducción y la lucha por los mercados, la diferencia de salarios, la desigualdad de los derechos de las mujeres con relación a los hombres, la inserción del trabajo femenil e infantil frente a los bajos salarios de los trabajadores, los derechos laborales constitucionales, la necesidad de la unión entre los trabajadores para defender sus derechos, la igualdad entre los hombres de diferente color, las guerras, entre otros. Se mencionan causas, efectos y posibilidades de cambio.

La Revolución mexicana tiene un lugar especial. Se presentan sus personajes principales -Madero y Zapata- y los logros que dejaron: la legislación laboral y la reforma agraria. Son motivo de análisis los documentos normativos que contienen estos asuntos, la situación del 
México de entonces y los logros del gobierno encabezado por Cárdenas: reparto de tierras, reforma educativa, mejoramiento de condiciones para los trabajadores y expropiación de la industria petrolera. Se resalta "La tendencia a recobrar para México lo que es de México" (SEP, I940, p. 28I).

El libro de texto Sexto Año. Serie SEP era acompañado con un Cuaderno de Trabajo en el que los alumnos hacían sus ejercicios relacionados con las lecturas. Este recurso fue de un tamaño mayor, pero de menos páginas. Contenía adivinanzas como: Origina el crimen, la locura y la muerte, usado con torpeza, ¿qué es?, la respuesta: el alcohol. En los ejercicios se pide a los alumnos -por ejemplo- redactar algunos párrafos del Artículo $3^{\circ}$ Constitucional, después de haberlo leído en el libro; o bien, escribir diálogos posibles entre explotados y explotadores en defensa de la propiedad; argumentar sobre la invalidez del derecho divino de los gobernantes y la crueldad de la conquista. En un pasaje aparece un conquistador en Cuba que dice a los esclavos que al cielo irían los buenos cristianos y uno de ellos contesta que él quería entonces ir al infierno, para no encontrarse con sus opresores. La consigna para el maestro era despertar la discusión de los alumnos sobre el tema.

En otros ejercicios se buscaba que la historia y la geografía fueran juntas. Incluyen la evolución de los pueblos más importantes y su ubicación en mapas para colorear; la historia de las guerras mundialesestamos en 1940-, causas y consecuencias; luchas por los mercados; los imperialismos y los monopolios. El Cuaderno de Trabajo incluye interesantes ejercicios, además de instrucciones sencillas para la fabricación de objetos y máquinas simples para el trabajo del hombre, por ejemplo: la carretilla y el tractor.

\section{Los libros escolares de la serie Rosas de la Infancia}

Con respecto a la serie de libros de Ma. Enriqueta Camarillo, titulada Rosas de la infancia, comenzó a publicarse -de acuerdo con algunos investigadores- entre I9I3 y I9I4, por la editorial de la viuda de Charles 
Bouret; mientras que el de sexto grado se publicó hasta la década de I950, como señala Aurora Ocampo en el Diccionario de escritores mexicanos. El último registro de la obra se encontró en una edición de I 987 y si esto fue así, entonces se publicó por cerca de cuarenta años.

Pero, ¿quién fue Ma. Enriqueta?, ¿cuáles fueron los contenidos de sus libros que se recomendó fueran retirados de las escuelas socialistas? María Enriqueta Camarillo y Roa Vda. de Pereyra (I872-I968) nació en Coatepec, Veracruz. Vivió fuera del país cerca de cuarenta años, especialmente en España, donde tuvo su etapa literaria más productiva. La autora "[...] se aferró a un mundo y a sus valores, tratando de transmitirlos a otras generaciones, en tiempos y circunstancias muy distintas a aquéllas en las que fueron concebidas" (Galindo, 20I6, p. IO2). Sus libros, concebidos para ser leídos en México, utilizaban un lenguaje descontextualizado e incluían una visión del mundo social que no concordaba con un país que iba en pos de confirmar su liberalismo político, frente a una España eminentemente católica y que estaba bajo la dictadura franquista iniciada en $\mathbf{9 3 6 .}$

Ma. Enriqueta se formó en los cánones de un férreo catolicismo. Su educación fue esmerada y contó con maestra de piano y traductora de idiomas, especialmente de francés, aprendió todo lo que era propio y necesario para una señorita de su posición social. Cuando la familia se traslada a México por las tareas políticas de su padre -Alejo Ambrosio Camarillo Rebolledo-, Ma. Enriqueta se inicia como escritora con sus primeros trabajos que se publicaron en la Revista Azul, encabezada por el modernista Luis G. Urbina. "Escritores contemporáneos de la talla de Amado Nervo, Rubén Darío, Manuel Gutiérrez Nájera, Alfonso Reyes y José Vasconcelos reconocían su talento" (Galindo, 20I6, p. I09).

En I898, Ma. Enriqueta se casó con el historiador, abogado, periodista y diplomático mexicano Carlos Pereyra y dadas sus actividades, vivieron juntos en ciudades como Washington, La Habana y varias más de Europa, hasta llegar a Madrid, donde publicó sus obras: poesías, cuentos, novelas, relatos de viaje y libros escolares. 
La autora, según las palabras que dejó escritas en los prólogos de sus libros, se proponía integrar a los niños a la sociedad en la que vivían, fomentando en ellos los valores morales más altos, modales y costumbres correctas, y un lenguaje adecuado y conveniente, que les permitiera un sano desarrollo en el núcleo social en el que se desenvolvían. De ahí el contenido de sus cuentos, leyendas, fábulas y biografías, en el que exalta lo que ella considera positivo en la formación moral del ser humano y donde también reprueba lo que asume como negativo.

El libro de sexto grado es un poco más grande que los anteriores de la misma serie y que los que aquí se analizan. Desde la pasta se percibe más sencillo, lo mismo que las ilustraciones interiores que se elaboran con base en líneas, como las del libro de la Serie SEP. A pesar de ello, los contenidos y propósitos se mantienen firmes como los de toda la serie:

[...] con el fin de ir paulatinamente despertando las mentes infantiles a la curiosidad y al saber, cuidando siempre de mover los buenos sentimientos y excitar sus inclinaciones sanas, haciendo hincapié en dar la máxima importancia al ambiente moral. (Ma. Enriqueta, citada en Galindo, 20I6, p. II4).

Si bien no todas las historias contenidas en las lecturas son de la autoría de Ma. Enriqueta, sí son fundamentalmente fantasiosas. Se habla de mundos inexistentes y lejanos. Algunos lugares y personajes que se mencionan tienen que ver con España, no con México, ¿qué le habrá significado a un niño mexicano hablar del castillo de Turégano o lugares de Portugal, o de Colón y Cervantes en lugar de Cuauhtémoc o Hidalgo? Niños que se nombran, por ejemplo, Paquín, cuando en México no se les llamaba así. Los relatos hablan de bellas ciudades habitadas por "familias bien", viviendo en buenas condiciones materiales y ayudadas por fieles sirvientes. La autora incluye algo de su biografía en la lectura titulada De mis recuerdos, donde señala que las "las familias bien" -como la suya- eran aconsejadas a ayudar a los más necesitados. 
El libro para sexto grado inicia con un escrito de la autora: Mi saludo a México y está fechado el I4 de marzo de i948:

Después de haber estado más de treinta y seis años ausente de México, hoy, que vuelvo a él, no ceso de exclamar a cada momento: -¡Al fin! ¡Al fin me veo en mi amadísima Patria! (Camarillo, I962, p. 9).

La autora da gracias a Dios que "pone ante mi vista" la Patria querida. El faro que ve llegando a Veracruz parece decirle: "iVenid, venid, que aquí os espero con ansia y con amor!” ¿Así se hablaba en el México de entonces? El barco en el que venía la escritora tuvo problemas para atracar en el puerto, una tormenta lo hizo retrasar su llegada, como si "un hado perverso nos arrojaba de ahí". Al comparar este texto con los anteriores de la misma serie -escritos para los grados de primero a quinto de primaria- se perciben menos contenidos de religión y de enseñanzas morales, más de cultura general y sobre el bien hablar y escribir.

En el texto para sexto grado se sigue haciendo hincapié en el amor a Dios; a la Patria y sus símbolos; a los héroes, entre quienes sobresale Hidalgo a pesar de lo breve de la biografía contenida: "Era un hombre de edad, lleno de canas y de dolores físicos y morales". También aparece sor Juana, santa y perfecta, como la califica la misma Ma. Enriqueta, quien también escribe sobre su esposo: "Cierro los ojos y me parece verlo al lado del Señor, puesta la mirada en Él, arrodillado humildemente a sus pies, y sonriendo con beatífica paz..." (Camarillo, I962, p. 25). Señala los valores que un niño debe cultivar, especialmente la perseverancia, la gratitud, la disciplina y el orden. Con respecto a la conquista de México y América, se explica cómo lo sucedido fue resultado del encuentro entre una civilización más avanzada sobre una más atrasada. Así lo prueban adelantos materiales y espirituales, especialmente la religión:

[...] una religión eminentemente humana, que enseña la igualdad y la fraternidad entre los hombres, ocupó el puesto de 
las creencias supersticiosas que tenían por fundamento el odio, y que imponían la práctica de los sacrificios humanos (Camarillo, I962, p. 36).

El autor de esta lectura fue el historiador Carlos Pereyra, esposo de Ma. Enriqueta. Sobre Colón ella misma escribe que: "pasó a una barca llevando el estandarte real, y fue quien primero puso el pie sobre aquella tierra bendita de la cual es el segundo creador" (Camarillo, 1962, p. 57). ¿Alguien más, además de Ma. Enriqueta, ha llamado a Colón segundo creador de América?, obvio que el primero es Dios. Cuando la autora regresó a México, este libro tal vez ya lo había escrito y compilado en España y sólo agregó la lección inicial referente a su regreso a México. Fue publicado en el gobierno de Miguel Alemán, un periodo de represión contra todo lo que se asociara con la izquierda y el comunismo.

\section{El libro de lectura actual}

El libro de lectura que hoy manejan los niños de sexto grado fue publicado por la SEP y está destinado para todos los alumnos de las escuelas primarias del país, aunque en la gran mayoría de los planteles particulares utilizan otros materiales como los de la serie Léeme, de Francisco Hinojosa, que incluso llegan a tener mayor uso.

El libro es de pasta suave, de tamaño semejante a los otros textos analizados, contiene diversas ilustraciones a color que facilitan la lectura y la portada igual a la que manejan otros textos publicados por la SEP: una mujer morena con la bandera en la mano, representado a la Patria, obra de Jorge González Camarena (ver figura 3). Su tamaño es menor que los de las otras materias escolares del mismo grado, sin embargo, por su número de páginas -I56- es el más breve de los textos estudiados en este trabajo. 


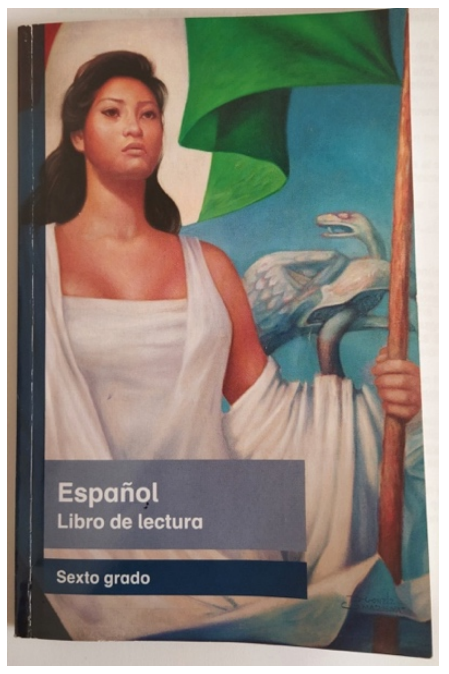

Figura 3. Portada del libro de lectura de sexto grado publicado por la SEP.

El texto Español. Libro de lectura es también una compilación de trabajos de diversos autores y al inicio aparece un mensaje que el Secretario de Educación (no aparece nombre) envía a los usuarios -alumnos y maestros- para que se eleve entre ellos el nivel de lectura, escritura y comprensión. Se editó por primera vez en 2014 con dimensiones mayores a las que tiene en la edición actual posteriormente se suprimió la lectura El primer beso, que trata sobre un niño que, al besar una estatua de mujer, "Se había hecho hombre". El texto fue reeditado para los ciclos escolares 2018-2019 y 2019-2020.

En las primeras páginas aparecen instrucciones sencillas dirigidas a los maestros, donde también se les desea éxito en su trabajo. A los alumnos les dan una lista muy breve de los derechos que poseen como lectores del libro. Posteriormente aparecen un par de melodías muy conocidas en el cancionero mexicano: El sube y baja y Adiós mi chaparrita. En esta obra hay algo importante que no se encontró en las demás y que corresponde con una recomendación al final de la lección para ahondar en el respectivo tema; tal vez con la idea de ayudar a los alumnos a que reconozcan que son capaces de leer. 
El número de lecturas y la variedad de temas son menores que los otros textos. Sobresalen dos lecturas por su tamaño: No era el único Noé, de la escritora coahuilense Magolo Cárdenas (n. 1950) y Palabras de Caramelo, de Gonzalo Moure, escritor español (n. 195I). En la primera se habla de las diferencias que existen entre los diversos grupos humanos que habitan la Tierra, las regiones que ocupan los animales en ella; así se reúnen habitantes de Asia, África y el Polo Norte con otros encabezados por Upi, un personaje un tanto loco y feliz quien guía un grupo de animales fantásticos. Todos siguen las órdenes de El que todo lo sabe, quien los salvó de un diluvio universal a ellos, a su familia y a los animales. El segundo relato narra la amistad de un niño sordo mudo con un pequeño camello, en quienes nace una relación semejante a la que surge entre los seres humanos, cuando son amigos sinceros.

El libro contiene noticias sobre trabajos científicos aplicados en la producción del aguacate hass, la historia de los grafitis en las ciudades y sus orígenes coloniales en las iglesias y los murales didácticos utilizados por los evangelizadores; el arte popular mexicano como los tapetes de aserrín. Otros relatos se refieren a los recuerdos de familia, por ejemplo, los de Alfonso Reyes y hay poesías en náhuatl, maya y zapoteco.

Llama la atención que se incluye el cuento La Cenicienta de los hermanos Grimm, e inmediatamente después el relato El almohadón de plumas, contenido en la colección de Horacio Quiroga: Cuentos de amor, de locura y de muerte. No se sabe qué tanto un niño de sexto grado de hoy todavía se ilusione y le guste leer el cuento de la Cenicienta, en el que "todos terminan muy felices", para pasar después a la lectura El almohadón de plumas. La pregunta es, ¿cuál es el hilo que une a la cenicienta con el siguiente cuento? Lo mismo aplica para el resto de las lecturas.

En el texto hay escasa información sobre las condiciones del México de hoy, su historia y personajes, lo mismo sobre los valores humanos a seguir e imitar; tal vez esto se trate en otros libros escolares, en este no.

\section{Conclusiones}


En este trabajo se confirmaron las preguntas iniciales, una vez que se analizó el contenido de libros de lectura, especialmente los utilizados durante el cardenismo y el de la época actual. Los proyectos sociales se manifestaron en ellos.

La reforma educativa de 1934 y la de hoy, pretenden lograr cambios profundos en la educación, los cuales redundarán en la sociedad entera, pero esto se refleja mucho más en los libros de lectura cardenistas que en los de la época actual.

Los libros del cardenismo fueron rechazados por algunas personas importantes de la época, por ejemplo, el profesor Gildardo Avilés, profesor egresado de la famosa Normal de Jalapa, quien calificaba los materiales de la SEP como "[...] ajenos a los intereses de los niños, llenos de dislates científicos y faltas de ortografía, impropios, por su fealdad, de ponerse en manos infantiles" (Meneses, I988, p. I72). Sin embargo, el libro de la Serie SEP, el de Hidalgo Monroy y el de Cuervo Martínez, son coherentes con la reforma educativa y siguen la misma línea en su elaboración. Sus contenidos se ajustan a los adelantos de la ciencia y la tecnología e incluyen temas relevantes del momento: los inventos que hacían más fácil la vida del hombre y aceleraban la producción de mercancías y la transformación de la naturaleza; la vida de los grandes científicos; la legislación de entonces, especialmente la referida a los trabajadores tanto del campo como de la ciudad; los derechos ciudadanos y la situación del país. Explicaban la historia como producto de desigualdades y enfrentamientos sociales provocados por el abuso de unos sobre otros e incluían relatos de héroes nacionales como Hidalgo, Morelos y Juárez, además de los aportes que hicieron para cambiar la historia del país.

Los ejes que guiaron la selección de lecturas durante el gobierno de Cárdenas fueron las transformaciones sociales que entonces se estaban dando, especialmente con respecto a la reforma de la misma educación, la organización de los trabajadores y el reparto de ejidos a los campesinos. Se buscaba detonar el cambio que fuera posible gracias a la participación no de un solo individuo, sino a la organización grupal y 
consciente, donde los intereses y beneficios colectivos se impusieran sobre los individuales.

Con relación a los libros de Ma. Enriqueta que circulaban entonces, había hilos conductores en las lecturas, que se fundamentaban en la idea de la inamovilidad social, pues todo era obra divina y por lo tanto así debía permanecer. Los cambios, si los había, serían lentos y sin violencia porque se daban gracias a la participación de los mejor posicionados socialmente, quienes -siendo hombres buenos- se preocuparían por el bienestar de los menos beneficiados.

Con respecto al libro de lectura de la SEP, que actualmente utilizan los alumnos de sexto grado, no se encontraron ejes conductores para la selección de las lecciones. En los agradecimientos se habla del "Comité del libro que participó en la preselección de las lecturas” (SEP, 20I7, p. 2) y tal vez sus integrantes sí tuvieron criterios que guiaron la selección de los autores, pero esto no se manifiesta de manera abierta.

En los textos utilizados durante el cardenismo y el de María Enriqueta, se manifiesta de manera explícita el tipo de ser humano que se quería formar en las escuelas, a través de la educación. En el de María Enriqueta el modelo era un ser humano bueno, virtuoso, profundamente religioso y preocupado por el entorno social. La base de su actuar eran los valores cristianos.

En el caso de los libros cardenistas, el ideal era formar buenos y responsables ciudadanos, comprometidos con el cambio de México. Ellos debían procurar mejores condiciones de vida para todos los mexicanos, poniendo siempre el interés común por encima del

\section{4 personal.}

En el texto que hoy utilizan los alumnos de sexto grado no se habla del ideal del ser humano que se trata de formar. Tampoco de los valores humanos que se consideran necesarios para el buen vivir. Sin embargo, en las lecturas se pueden deducir algunos: la familia, la amistad, la tolerancia, el respeto frente a diferencias y el reconocimiento de los 
indígenas, su cultura y sus lenguas; aunque no aparece de manera abierta y las interpretaciones que se hagan pueden ser subjetivas y personales.

La SEP podría ocupar estos materiales escolares de manera mucho más provechosa para la conformación axiológica de los alumnos, de acuerdo con el proyecto social que la educación se ha planteado en la formación de los seres humanos. ¿Cuál es el ideal de ser humano que hoy contiene y pretende alcanzar el nuevo proyecto educativo nacional?, se deja esta pregunta y otras más para posteriores investigaciones.

\section{Referencias}

Camarillo, M. E. (1962). Nuevas Rosas de la infancia. Sexto Año. México: Patria.

Cárdenas, L. (1978). Palabras y documentos públicos de Lázaro Cardenas, I928-1970. I, Mensajes, discursos, declaraciones, entrevistas y otros documentos : 1928-1940. México: Siglo XXI editores.

Cuervo Martínez, F. (1936). México. Libro nacional de lectura para uso de los alumnos de sexto año de la escuela primaria. México: Patria.

De la Borbolla, Ó. (2019). La rebeldía del pensar (Col. Breviarios, 6oo). México: Fondo de Cultura Económica.

De Luca, M. (2018). La construcción de valores nacionalistas e ideológicos en los libros de texto mexicanos e italianos (I930-I94I). Iconografías comparadas. Ponencia presentada en el XV Encuentro Internacional de Historia de la Educación. Sociedad Mexicana de Historia de la Educación. Pachuca, Hidalgo. Recuperado de: http://somehide.org/index.php/actividades-noticias2/ponencias-XV-encuentro\#.XkcugkN7n-Z 
Galindo Peláez, G. A. (20I6). Formar en los corazones el culto por lo bueno y lo bello. Acercamiento a María Enriqueta Camarillo y Rosas de la infancia. En L.E. Galván Lafarga, L. Martínez Moctezuma y O. López Pérez (coords.), Más allá del texto: autores, redes del saber y formación de Lectores (pp. IOI-I24). México: Centro de Investigaciones y Estudios Superiores en Antropología Social / Universidad Autónoma del Estado de Morelos / El Colegio de San Luis.

Galván Lafarga, L. E. (2004). Arquetipos, mitos y representaciones en libros de historia patria (1934-I939). En C. Castañeda García, L.E. Galván Lafarga y L. Martínez Moctezuma (coords.), Lecturas y lectores en la historia de México, (pp. I63-I76). México: Centro de Investigaciones y Estudios Superiores en Antropología Social / Universidad Autónoma del Estado de Morelos / El Colegio de Michoacán.

Giraudo, L. (2004). Lectores campesinos, maestros indígenas y bibliotecas rurales. Puebla y Veracruz (I920-I930). En C. Castañeda García, L.E. Galván Lafarga y L. Martínez Moctezuma (coords.), Lecturas y lectores en la historia de México, (pp. 303-326). México: Centro de Investigaciones y Estudios Superiores en Antropología Social / Universidad Autónoma del Estado de Morelos / El Colegio de Michoacán.

Hidalgo Monroy, L. (1938). ¡Levántate!. Libro Sexto de Lectura para uso de los alumnos de las escuelas primarias. México: Herrero Hermanos Sucesores.

Mendoza Ramírez, M. G. (2009). La cultura escrita y los libros de texto de historia oficial en México I93I-1959. México: El Colegio Mexiquense, A.C.

Meneses Morales, E. (1988). Tendencias educativas oficiales en México I934I964. México: Universidad Iberoamericana. 
Montes de Oca Navas, E. (2010). Libros de lectura utilizados en las escuelas primarias mexicanas, 1920-I940. En L.E. Galván Lafarga y L. Martínez Moctezuma (coords.), Las disciplinas escolares y sus logros, (pp.337-36I). México: Centro de Investigaciones y Estudios Superiores en Antropología Social / Universidad Autónoma del Estado de Morelos / Juan Pablos Editor.

Rockwell, E. (1996). Hacer escuela. Transformaciones de la cultura escolar, Tlaxcala I9IO-I940 [Tesis doctoral]. Centro de Investigación y de Estudios Avanzados del Instituto Politécnico Nacional / Departamento de Investigaciones Educativas, México.

SEP. [Secretaría De Educación Pública]. (1940). Sexto Año. Serie SEP, Escuelas Primarias Urbanas. México: Comisión Editora Popular de la Secretaría de Educación Pública.

SEP. (1940). Cuaderno de Trabajo, Sexto Año. Serie SEP, Escuelas Primarias Urbanas. México: Comisión Editora Popular de la Secretaría de Educación Pública.

SEP. (2017). Español. Libro de lectura. Sexto grado. México: Secretaría de Educación Pública.

Vaughan, M. K. (2000). La política cultural en la revolución. Maestros, campesinos y escuelas en México 1930-I940. México: Secretaría de Educación Pública / Biblioteca para la actualización del Maestro / Fondo de Cultura Económica.

Este artículo se publica bajo una licencia de Creative Commons Reconocimiento-NoComercial 4.0 Internacional, y puede ser usados gratuitamente para fines no comerciales, dando los créditos a los autores y a la revista. 